\title{
Trayectoria del sistema de innovación del cultivo de girasol en México, 1965-2018
}

Angélica Torres-Ávila, Jorge Aguilar-Ávila, Vinicio Horacio Santoyo-Cortés y EnRiQue Genaro Martínez-GonZález

\begin{abstract}
PALABRAS CLAVE: sistema de innovación agrícola, trayectoria tecnológica, cadenas agroalimentarias, agroindustria.
\end{abstract}

\author{
CÓDIGOS JEL: O31, O33, O35, Q16.
}

e explica la evolución del cultivo de girasol en México en el marco de las tran-

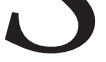
siciones agroalimentarias globales respecto del consumo de grasas. Se utilizó el enfoque de sistema de innovación (SI), el cual es adecuado para estudiar un cultivo emergente en el contexto del patrón tradicional de cultivos de la agricultura nacional. La información se obtuvo de publicaciones y datos estadísticos publicados en el periodo de 1965 a 2018 y de entrevistas semiestructuradas con actores clave. La información recabada se ordenó cronológicamente, identificando actores y eventos relevantes que han afectado, tanto la trayectoria del cultivo como la configuración del SI. Los resultados muestran que la introducción de girasol respondió a la demanda de aceite y grasas vegetales como una alternativa viable para los agricultores y la industria alimentaria. No obstante, su desarrollo como cultivo comercial se ha subordinado al uso de otras oleaginosas de las cuales se obtienen subproductos que al sumar su valor al del aceite son más atractivas para la industria. Sin embargo, el mejoramiento genético del girasol ha derivado en nuevos genotipos a partir de los cuales se obtiene aceite con propiedades deseables para la salud humana. Esto abre una nueva posibilidad de expansión del cultivo. 


\title{
Trajectory of sunflower innovation system in Mexico, 1965-2018
}

\section{KEYWORDS: agricultural innovation system, trajectory, agri-food chains, agro-industry.}

\author{
JEL CODES: O31, O33, O35, Q16.
}

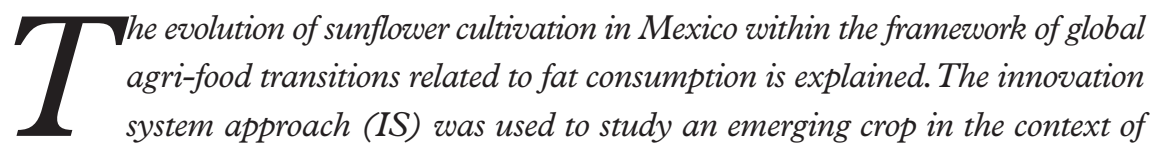
the traditional national food production patterns. The information was collected from publications and statistical data published between 1965-2018 and from semi-structured interviews with key actors. The information collected was ordered chronologically, identifying relevant actors and events that have affected the crop's trajectory and the IS configuration. The results show that the introduction of sunflower responded to the demand for vegetable oil and fats as a viable alternative for farmers and the agri-food industry. However, its development as a commercial crop has been subordinated to the use of other oilseeds from which by-products are obtained, which by adding their value to that of vegetable oil are more attractive to the industry. Nevertheless, the genetic improvement of sunflower has resulted in new genotypes from which oil is obtained with desirable properties for human health. This opens a new possibility of crop expansion.

Recepción: 2019-08-08 - Revisión: 2020-03-05 - Aceptación: 2020-03-30

Angélica Torres-Ávila [orcid.org/0000-0002-3663-2902] es estudiante de doctorado en Problemas Económico Agroindustriales en la Universidad Autónoma Chapingo-Centro de Investigaciones Económicas Sociales y Tecnológicas de la Agroindustria y la Agricultura Mundial. Dirección para correspondencia: km 38,5 Carretera México-Texcoco, 56230 Chapingo (México).C.e.: atorres@ciestaam.edu.mx

Jorge Aguilar-Ávila [orcid.org/0000-0002-6129-7050] es profesor-investigador en la Universidad Autónoma Chapingo-Centro de Investigaciones Económicas Sociales y Tecnológicas de la Agroindustria y la Agricultura Mundial. Dirección para correspondencia: km 38,5 Carretera México-Texcoco, 56230 Chapingo (México).C.e.:jaguilar@ciestaam.edu.mx

Vinicio Horacio Santoyo-Cortés [orcid.org/0000-0003-0400-1724] es profesor-investigador en la Universidad Autónoma Chapingo-Centro de Investigaciones Económicas Sociales y Tecnológicas de la Agroindustria y la Agricultura Mundial. Dirección para correspondencia: km 38,5 Carretera México-Texcoco, 56230 Chapingo (México).C.e.: hsantoyo@ciestaam.edu.mx

Enrique Genaro Martínez-González [orcid.org/0000-0001-9312-5002] es profesor-investigador en la Universidad Autónoma Chapingo-Centro de Investigaciones Económicas Sociales y Tecnológicas de la Agroindustria y la Agricultura Mundial. Dirección para correspondencia: km 38,5 Carretera México-Texcoco, 56230 Chapingo (México).C.e.: enriquemartinez@ciestaam.edu.mx 


\section{INTRODUCCIÓN}

Los resultados de las investigaciones y la rapidez con la que surgen nuevos conocimientos sobre los efectos de las grasas en la nutrición humana tienen consecuencias trascendentales para los consumidores, los responsables del cuidado de la salud, los agricultores y la industria agroalimentaria.

De este modo, un caso importante de cambio en el sistema alimentario mundial lo constituye el crecimiento en la oferta y la demanda de aceites y grasas vegetales de bajo costo. Su uso comestible fue impulsado por problemas de salud relacionados con el consumo de grasas animales (Downs, Thow \& Leeder, 2013; Monge-Rojas et al., 2011; World Health Organization, 2018) y por los avances tecnológicos en el procesamiento de aceites vegetales (Shields, 2010; Veit, 2019).

Esta transición en el consumo de grasas con relación al remplazo de las grasas de origen animal por las grasas de origen vegetal, ocurrida a mediados del siglo $\mathrm{xx}$, ha tenido implicaciones en el desarrollo agrícola de los países, pues varias oleaginosas fueron incorporadas al patrón tradicional de cultivos para abastecer la demanda creciente de aceite vegetal; tal es el caso de México.

En México el uso creciente de aceites y mantecas (vegetales y mixtas) en la alimentación comenzó en la década de 1940 (Arroyo, 1989; INEGI, SECOFI \& SISVAN, 1988). De manera que, a partir de 1960, la producción de oleaginosas cobró especial importancia debido a la incorporación de soya y cártamo al patrón de cultivos de la agricultura nacional (Flores, Sánchez Peña \& Santoyo, 1986; Sánchez Peña, 1993). No obstante, a pesar del incremento de la producción doméstica de soya y cártamo, se empezó a recurrir a la importación de semillas oleaginosas y aceite crudo vegetal.

En consecuencia, el girasol se vislumbró como una opción para enfrentar la escasez de aceite vegetal (Gallegos \& Elizondo, 1972). Su incorporación al patrón de cultivos de la agricultura nacional se inició en la década de 1970 a través de intervenciones gubernamentales (Ortegón, 1980). A pesar de esto, el girasol no logró integrarse como un cultivo comercial más amplio y mantuvo una superficie marginal e intermitente. En las últimas dos décadas, por razones relacionadas con el efecto de las grasas trans en la salud, la industria alimentaria ha manifestado interés en la producción nacional de girasol alto oleico para la obtención de aceite, debido a sus cualidades nutricionales y funcionales.

La trayectoria que ha seguido el girasol en México se puede ilustrar en varios escenarios de comportamiento, cuyo análisis aporta evidencia sobre su desarrollo como tec- 
nología determinado por las particularidades de la industria aceitera y circunscrito a los procesos de transición agroalimentaria global. Por tanto, el objetivo de este documento es comprender la evolución del cultivo de girasol en México en el marco de las transiciones agroalimentarias globales respecto del consumo de grasas. Para tal fin, se utiliza como marco analítico el enfoque del sistema de innovación (SI); este enfoque es especialmente apropiado para analizar el cambio tecnológico, donde se expone que las tecnologías deben estar acompañadas por cambios organizativos, institucionales, de mercado y técnicos, integrados en una red de actores heterogéneos (Klerkx, Mierlo \& Leeuwis, 2012).

\section{EL SISTEMA DE INNOVACIÓN COMO MARCO ANALÍTICO}

El enfoque del sistema de innovación (SI) tiene su origen en la década de 1980, y se utiliza para explicar el éxito económico de países desarrollados con economías industrializadas y un sólido historial de innovación (Freeman, 2004; Lundvall, 2015). Desde inicios de este siglo, este enfoque se ha extendido en el sector agroalimentario como un marco adecuado para el análisis de la innovación (Banco Mundial, 2008; Hall et al., 2001), influenciado por las contribuciones de las variantes del SI y la evolución de otros enfoques sistémicos en los estudios de la innovación propios del sector (Klerkx, Mierlo \& Leeuwis, 2012).

Desde la perspectiva del SI se reconoce que la innovación tiene lugar a través de la interacción entre múltiples actores (Hall, Mytelka \& Oyeyinka, 2005). Por tanto, su éxito se explica parcialmente por el grado en el que se reúnen actores con capacidades, información y recursos variados (Spielman et al., 2009) con el fin de generar, intercambiar y aplicar conocimiento. Los flujos de conocimiento que ocurren son multidireccionales y permiten desarrollar circuitos de retroalimentación que estimulan la construcción de competencias, el aprendizaje y la adaptación (Banco Mundial, 2008). Tanto el intercambio de conocimientos como el aprendizaje, procesos clave de la innovación, se ven influidos por los entornos socioeconómicos e institucionales, pues definen la manera en que los actores interactúan y se relacionan (Hall et al., 2001; Hall et al., 2005).

Un SI posee dos dimensiones: a) los límites del sistema; y b) el tiempo (Carlsson et al., 2002). Con relación a los límites, el sistema de innovación agrícola (SIA) se ha delineado considerando el sector completo de un país, por subsectores, por actividad productiva, incluyendo solo a los agricultores o analizando una trayectoria particular de cambio tecnológico (Clark et al., 2003; Lamprinopoulou et al., 2014; Ortiz et al., 2013). 
Aunque el SIA puede definirse a diferentes niveles para su análisis, el más relevante es aquel que se orienta en niveles cada vez más específicos, configurados para atender problemas particulares (Anandajayasekeram \& Gebremedhin, 2009). El análisis de un sistema de naturaleza más específica permite aproximarse mejor a la comprensión del contexto en el que las innovaciones se producen (Arocena \& Sutz, 2003). En este sentido, la cadena de valor puede constituir el punto de partida más adecuado en la delineación del SIA (Anandajayasekeram \& Gebremedhin, 2009). En cuanto a la dimensión tiempo, la fotografía instantánea de un SI en un momento determinado puede diferir sustancialmente de otra fotografía instantánea del mismo sistema en un momento diferente (Carlsson et al., 2002).

Así, un SIA está integrado por tres elementos que pueden variar en el tiempo: a) los componentes estructurales que incluyen a los actores, las redes y las instituciones; b) las interacciones que ocurren a través de los actores e instituciones; y c) los atributos, definidos como las propiedades de los componentes y de las relaciones entre ellos (Carlsson et al., 2002), manifestadas en las funciones que se despliegan para apoyar los procesos de innovación (Hekkert et al., 2007).

Tradicionalmente, los trabajos sobre SI se han basado en la identificación de los componentes estructurales en un momento específico, predeterminando al sistema como una estructura preestablecida y estática, lo cual no explica cómo se produce un SI ni si la estructura es adecuada o no. Alternativamente, atendiendo a la naturaleza dinámica de un SI, varios autores han desarrollado un marco de análisis más amplio basado en el mapeo de las funciones del SI (Bergek et al., 2008; Hekkert et al., 2007; Hekkert \& Negro, 2009). La diferencia entre ambas visiones es que la estructura de un SI muestra a los actores en el sistema, mientras que el análisis de la dinámica del sistema muestra lo que se está haciendo y si esto es suficiente para desarrollar innovaciones exitosas (Hekkert, Heimeriks \& Harmsen, 2011).

La literatura científica (Bergek et al., 2008; Hekkert et al., 2007; Hekkert \& Negro, 2009) identifica siete funciones esenciales: F1) actividades empresariales, en el núcleo de cualquier SI están los empresarios, quienes realizan experimentos, buscando y explotando oportunidades de negocio; F2) desarrollo del conocimiento, involucra la investigación y creación de conocimientos, requisitos previos para la innovación; F3) difusión del conocimiento, se refiere al intercambio de conocimientos y aprendizajes a través de las redes; F4) orientación de la búsqueda, se refiere a las actividades que dan forma a las necesidades, requisitos y expectativas de los actores; F5) formación del mercado, las nuevas tecnologías a menudo no pueden superar a las establecidas, por tanto, es necesario facilitar la creación de mercados, donde las nuevas tecnologías puedan desarrollarse; F6) movi- 
lización de los recursos, en la realización de las actividades dentro del SI son necesarios recursos financieros, de capital y humanos; y F7) creación de legitimidad, para que una tecnología se desarrolle y madure debe convertirse en parte del régimen existente e incluso tiene que derrocarlo, por tanto, los actores deben crear un lobby político que contrarreste esta inercia y respalde la nueva tecnología. Estas funciones interactúan entre sí, positiva o negativamente, para la construcción, mantenimiento y transformación de un SI.

En la Figura 1 se resumen los componentes del sistema, sus interacciones y el despliegue de las funciones, que son de naturaleza dinámica y varían con el tiempo. Esto muestra que el éxito de una innovación es dependiente de la trayectoria que sigue el SIA en términos de cómo se configura y funciona.

\section{FIGURA 1}

Marco conceptual para el análisis de un SIA

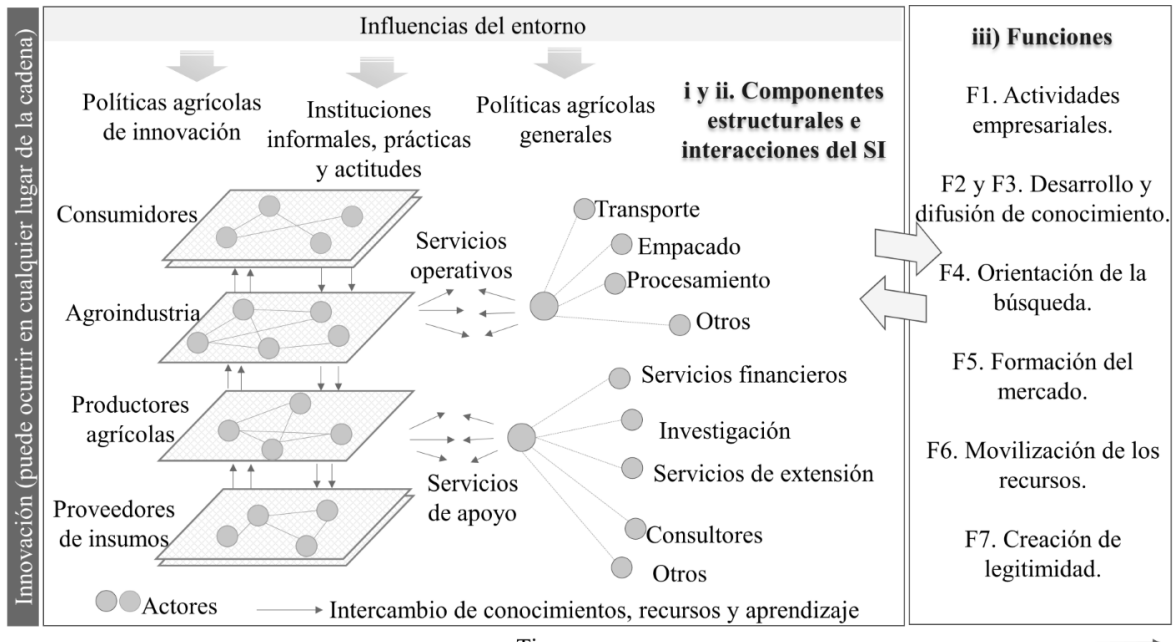

Fuente: elaboración propia a partir de información documental.

\section{MATERIALES Y MÉTODOS}

Para la integración y análisis de la información, se utilizó la técnica historial de eventos, aplicada en diversos estudios del SI, la cual consiste en la identificación, clasificación y análisis de eventos de acuerdo con las funciones del SI (Bergek et al., 2008; Hekkert et al., 2007; Hekkert \& Negro, 2009). Un evento es la unidad elemental de análisis, y se refiere a sucesos internos y externos que acontecen en un determinado momento, inclui- 
dos los actores involucrados. Un evento puede contribuir a las funciones del sistema positiva o negativamente.

Se utilizaron varias estrategias para la colecta de datos, lo cual permitió su comparación para garantizar su fiabilidad. Primero, se recopilaron 60 documentos en torno al cultivo de girasol, incluidos artículos, periódicos, libros, boletines, tesis, folletos, informes, documentos de sitios web, entre otros, publicados entre 1965 y 2018. En segundo lugar, se recabó información estadística de varias bases de datos (SIAVI, SIAP y FAOSTAT), obteniendo variables tales como superficie sembrada, producción y regiones productoras, importaciones y exportaciones de semilla y aceite de girasol. En tercer lugar, se realizaron entrevistas semiestructuradas a 17 actores clave que incluyeron instituciones de investigación, asesores técnicos, agricultores, instituciones gubernamentales, entre otros; las entrevistas se basaron en una línea común de preguntas, complementadas con cuestionamientos específicos según el tipo de actor.

Las preguntas orientadoras para la recopilación de la información se adaptaron de los planteamientos del Banco Mundial (2008) y Matsaert et al. (2005), y fueron las siguientes: ¿cuándo comenzó el desarrollo del cultivo?, ¿qué factores dispararon su surgimiento?, ¿quiénes han sido los actores clave en el pasado y en el presente y cuáles son sus características?, ¿fueron estos disparadores de tipo técnico, político, de mercado u otros?, ¿cómo ha cambiado el sistema productivo girasol?, chacia dónde se dirige ahora?

La información obtenida de las diferentes fuentes se sistematizó en orden cronológico, identificando eventos y actores involucrados relacionados con la trayectoria del cultivo de girasol. La identificación de los eventos se hizo de manera inductiva, utilizando como referencia el marco conceptual de las funciones del SI. Para resaltar la secuencia y relevancia de los eventos, la trayectoria del cultivo de girasol se dividió en tres etapas. El Cuadro 1 ofrece una descripción de los tipos de eventos utilizados para operacionalizar las funciones del SI.

Los eventos, los actores involucrados y el momento de aparición se clasificaron en alguna de las siete funciones del SI, según correspondiera. Por la accesibilidad a la información, la agrupación de eventos en funciones se hizo principalmente en la última etapa. Adicionalmente, en la última etapa las funciones se agruparon en funciones débiles o fuertes; esto de acuerdo con el criterio del investigador y con validación de actores clave, considerando el alcance de los eventos incluidos.

Para la presentación de la información, se utilizaron líneas de tiempo destacando los eventos más relevantes y mediante narración se ilustró la secuencia de los eventos, re- 
saltando las circunstancias que han posibilitado o impedido la configuración del SI girasol.

\section{CUADRO 1}

Tipos de eventos como indicadores de las funciones del SI

\begin{tabular}{ll}
\hline Función & Tipos de eventos \\
\hline F1. Actividades empresariales & $\begin{array}{l}\text { Participación en proyectos de innovación } \\
\text { Inversiones en una nueva tecnología }\end{array}$ \\
F2. Desarrollo del conocimiento & $\begin{array}{l}\text { Proyectos de investigación científica } \\
\text { Publicaciones científicas }\end{array}$ \\
F3. Difusión del conocimiento & $\begin{array}{l}\text { Actividades de difusión (talleres, cursos, capacitaciones) } \\
\text { Redes de información }\end{array}$ \\
F4. Orientación de la búsqueda & $\begin{array}{l}\text { Documentos de visión compartida } \\
\text { Acuerdos entre actores }\end{array}$ \\
F5. Formación de mercado & $\begin{array}{l}\text { Reclamaciones } \\
\text { Desgravaciones fiscales } \\
\text { Regulaciones que afectan directamente ciertos procesos de producción }\end{array}$ \\
F6. Movilización de recursos & $\begin{array}{l}\text { Subsidios } \\
\text { Inversiones públicas y privadas } \\
\text { Fctividades lobby }\end{array}$ \\
\hline
\end{tabular}

Fuente: elaboración propia a partir de Hekkert et al. (2007), y Hekkert y Negro (2009).

Por último, en la búsqueda y el análisis de la información referente a la tercera etapa del cultivo, el estado de Zacatecas destacó como un caso relevante en la producción de girasol alto oleico, ya que es el principal productor y desde la introducción del cultivo la producción ha mantenido un crecimiento sostenido. Por ello, se decidió analizar la trayectoria particular de la oleaginosa en ese estado.

\section{RESULTADOS}

\subsection{Dinámica histórica del cultivo de girasol en México}

La industria aceitera en México inició en 1890 con el aprovechamiento de las semillas de algodón, subproducto de la industria textil, que hasta ese entonces se quemaba (Flores, Sánchez Peña \& Santoyo, 1986; Sánchez Peña, 1993). La incursión en esta industria se relaciona con los avances que los Estados Unidos generaron referente al aprovechamiento de la semilla para la extracción de aceite (Veit, 2019), los cuales fueron transferidos a México (Sánchez Peña, 1993). 
A medida que el procesamiento del aceite de algodón mejoró en los Estados Unidos, este producto llegó a ser de uso comestible (Veit, 2019). No obstante, en el caso de México su uso fue limitado por considerarse como un producto inferior a la manteca de cerdo y a la mantequilla, productos tradicionalmente importados. Por tanto, el aceite de algodón y otros que le siguieron (el ajonjolí, el cacahuate y la copra) se utilizaron para la fabricación de jabones y pastas oleaginosas para exportación (Flores, Sánchez Peña \& Santoyo, 1986).

Mientras tanto, los Estados Unidos continuaron experimentando con el aceite de algodón. A finales del siglo XIX desarrollaron mezclas de grasas de cocina mixtas, hechas principalmente de aceite de algodón y solidificadas con grasa de res. Pronto se utilizó el proceso de hidrogenación mediante el cual este aceite se transforma en una grasa sólida parecida a la manteca de cerdo, comercializada a partir de 1911 (Shields, 2010; Veit, 2019). Este hecho marcó el inicio de los aceites vegetales hidrogenados en la alimentación.

Por otra parte, en México a partir de 1940 se aceleró notablemente el ritmo de crecimiento de la población y se incrementó la urbanización, procesos que en su conjunto condujeron al cambio de hábitos alimentarios (Arroyo, 1989; INEGI, SECOFI \& SISVAN, 1988). Así, productos de gran sustituibilidad como la manteca de cerdo, base de la cocina rural, fueron remplazados paulatinamente por los aceites vegetales en las grandes ciudades (Flores, Sánchez Peña \& Santoyo, 1986; Reig, 1985). Entre 1950 y 1955 la preferencia por el aceite vegetal se incrementó considerablemente (Sánchez Peña, 1993), situación asociada a la elevación de los precios de la manteca de cerdo, pues los aceites y grasas vegetales se cotizaron a precios menores (Bancomext, 1955).

$\mathrm{Al}$ inicio las principales fuentes de aceites vegetales hidrogenados en México eran la margarina y la manteca, utilizadas en los hogares para untar o como ingredientes. Paulatinamente los aceites vegetales líquidos se colocaron en la canasta básica compitiendo con las mantecas (vegetal y mixta). Además, se transitó a una segunda etapa, donde los aceites vegetales hidrogenados se utilizaron ampliamente en los productos alimenticios ultraprocesados.

En 1959 inició la crisis del cultivo del algodón en México debido a cambios en el mercado internacional de la fibra de algodón por la competencia de las fibras sintéticas y a problemas internos relacionados con su producción (Sánchez Peña, 1993). Esta situación coincidió con la introducción y expansión de otros cultivos oleaginosos, como la soya y el cártamo (Flores, Sánchez Peña \& Santoyo, 1986). 
Así, a inicios de 1960 la producción de oleaginosas cobró especial importancia debido a la incorporación de la soya y el cártamo al patrón de cultivos de la agricultura nacional (Arroyo, 1989; INEGI, SECOFI \& SISVAN, 1988; Sánchez Herrera \& Gómez Cruz, 1992).

La expansión de la soya y el cártamo se debió al crecimiento de la ganadería extensiva, que incluyó la incorporación de la soya, el cártamo y el sorgo para la elaboración de alimentos balanceados, esto como parte de la incorporación de un paquete transnacional impulsado por los Estados Unidos (Sánchez Herrera \& Gómez Cruz, 1992; Sánchez Peña, 1993). Dicha situación conllevó a valorizar estos cultivos también por su contenido de aceite. Paralelamente, se continuó con la sustitución de la manteca de cerdo por el aceite vegetal (Flores, Sánchez Peña \& Santoyo, 1986; Reig, 1985).

Aunado a los elementos de crecimiento de la población y la urbanización, en la década de 1960 se desarrollaron campañas de salud pública orientadas a disminuir el uso de grasas animales. En consecuencia, la industria alimentaria comenzó a utilizar cantidades sustanciales de aceites vegetales parcialmente hidrogenados en los alimentos procesados (industrias de la panificación, galletera, repostería y confitería, botanas y frituras).

A pesar del incremento de la producción de soya y cártamo, este no fue suficiente para atender a la demanda doméstica; en 1968 se comenzó a recurrir a la importación de aceites, semillas oleaginosas y sebos, marcándose así el fin de la autosuficiencia en México en el abasto de aceites y grasas comestibles. El girasol, ubicado en ese entonces en el segundo lugar entre las oleaginosas producidas en el mundo, se visualizó como una alternativa prometedora para enfrentar la escasez de aceite vegetal (Gallegos \& Elizondo, 1972), debido, tanto a su rendimiento industrial de aceite crudo ${ }^{1}$ y pasta como a su alta tolerancia a las sequías y a las bajas temperaturas, condiciones prevalecientes en las zonas de temporal (INEGI, SECOFI \& SISVAN, 1988). En consecuencia, se empezaron a gestar acciones para su introducción en México de manera más amplia.

Además de integrar al girasol en el patrón de cultivos nacional con la finalidad de obtener aceite, esta oleaginosa también se valorizó como una oportunidad más remunerativa que el maíz y el frijol para los agricultores, con potencial en regiones áridas y semiáridas (Amador, 1969; Fucickovsky, 1976; Robles, 1980); lo anterior debido a su capacidad para tolerar períodos cortos de estrés hídrico.

1. Su contenido de aceite es $40 \%$, mayor que el de soya (18\%) (KLEINGARTNER, 2002). 
En general, el girasol es un cultivo con adaptación a condiciones agroecológicas variadas, pues puede cultivarse desde áreas cercanas al nivel del mar hasta poco más de 2500 msnm de altura en condiciones de riego, humedad residual o temporal (INIFAP, 2004); por ello, su fomento se dio, tanto en regiones áridas y semiáridas (Zacatecas, Nuevo León, Coahuila, Durango, San Luis Potosí, Tamaulipas, entre otros) como en regiones subhúmedas (Valle de México, Morelos, Puebla, Hidalgo, entre otros) (Amador, 1969).

Se identifican tres etapas en la evolución del cultivo de girasol en México (Figura 2).

\section{FIGURA 2}

Evolución de la producción de girasol e hitos históricos en México, 1965-2018

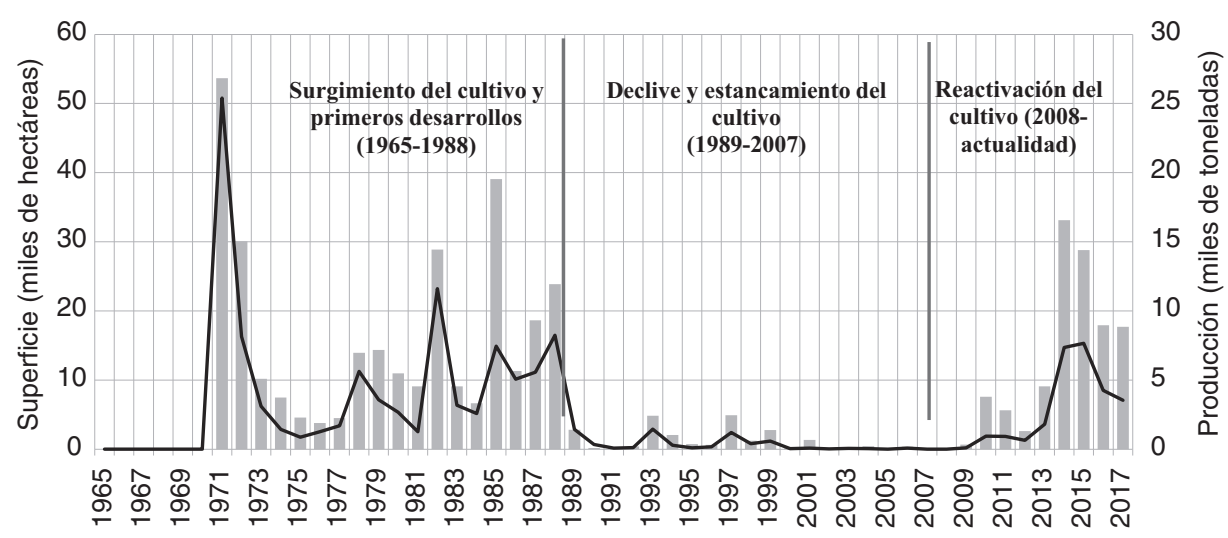

- Producción — Superficie cosechada

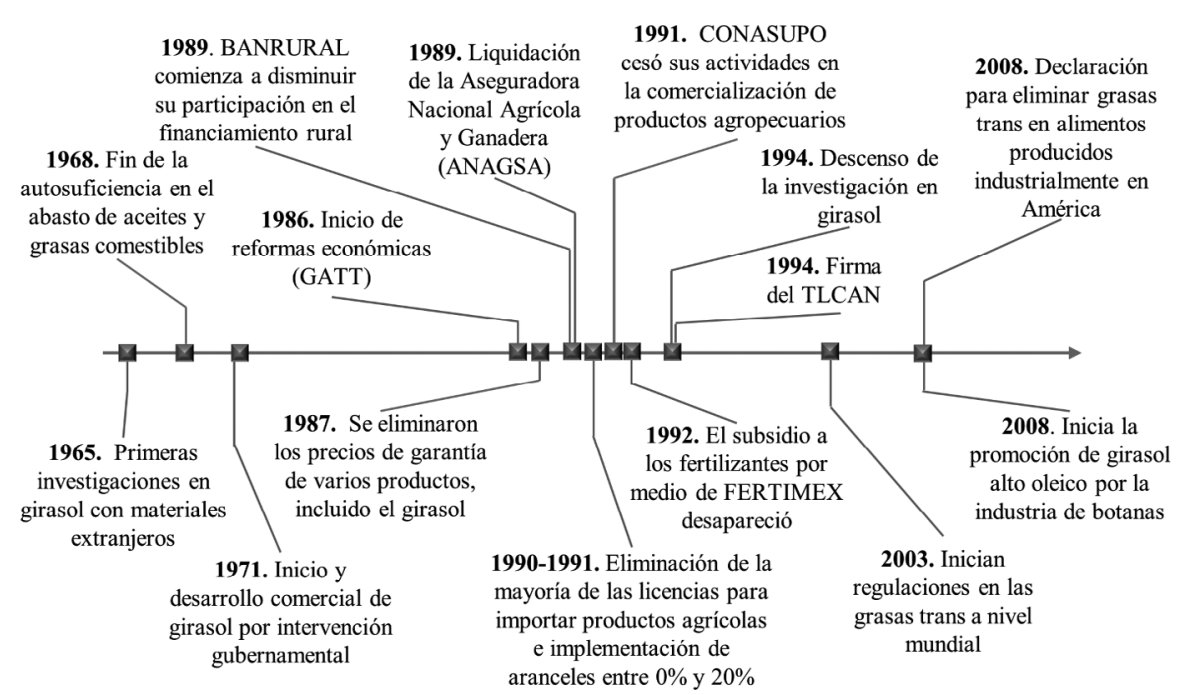

Fuente: elaboración propia a partir de información de SIAP (2018) y fuentes documentales. 


\subsubsection{Surgimiento del cultivo y primeros desarrollos (1965-1988)}

En el año 1965 se iniciaron las primeras investigaciones en girasol, concentradas principalmente en: a) pruebas de adaptación y rendimiento de materiales vegetales importados; b) desarrollo de programas de mejoramiento genético dirigido a la obtención de híbridos y variedades nacionales; y c) aspectos relacionados con el manejo del cultivo. En estas actividades estuvieron implicados principalmente el Instituto Nacional de Investigaciones Agrícolas (INIA) ${ }^{2}$ y el Instituto Tecnológico de Estudios Superiores de Monterrey (ITSEM) (Fucickovski, 1976; Gallegos, 1970; Ortegón, 1980; Robles, 1980).

El proceso para integrar al girasol al patrón de cultivos nacional contó con el apoyo de la Cámara Nacional de la Industria de Aceites, Grasas y Jabones, que en 1968 se interesó en los trabajos y resultados obtenidos por el INIA y propuso la elaboración de un programa de trabajo para incrementar las investigaciones y promover el cultivo (Amador, 1969).

Aunque se sabe que las colonias menonitas y otros agricultores ya cultivaban el girasol en pequeñas superficies para fines de autoconsumo en algunas regiones del país como Chihuahua, Coahuila, Zacatecas y San Luis Potosí, no es hasta el año 1969 cuando se inician las primeras siembras a nivel comercial en los estados de Puebla, Guanajuato, Morelos y Zacatecas (Ortegón, 1980). En 1971 la Secretaría de Agricultura y Ganadería $(\mathrm{SAG})^{3}$ decidió impulsar el girasol como cultivo de temporal (Ortegón, 1980, 1982; Pascalis, 1980). La superficie establecida fue de 50.776 hectáreas, distribuidas principalmente en Durango (20.122 ha), Guanajuato (15.985 ha), Zacatecas (10.000 ha) y Puebla (3.000 ha) (Torre, 1980). La producción de girasol se desarrolló utilizando variedades extranjeras, pues aún no se tenían variedades nacionales disponibles ${ }^{4}$.

Estas intervenciones y las que siguieron involucraron a varios actores. Entre estos se incluye la Secretaría de Agricultura y Ganadería (SAG), productores de cultivos básicos, INIA, ITSEM, universidades, asesores técnicos, una aseguradora agrícola, la Productora Nacional de Semillas (Pronase), el Banco Nacional de Crédito Agrícola (Banagrícola), el Banco Nacional de Crédito Ejidal (Banjidal), la Compañía Nacional de Subsistencias

2. Ahora el Instituto Nacional de Investigaciones Forestales Agrícolas y Pecuarias (INIFAP).

3. Equivalente al Ministerio de Agricultura, y ahora denominada Secretaría de Agricultura y Desarrollo Rural (SADER).

4. La primera variedad desarrollada fue Tecmon 1 obtenida en 1980 por el ITESM, seguida por la variedad Victoria obtenida en 1983 por el INIFAP, ambas para la producción de aceite (ORTEGÓN \& Escobedo, 1987a, 1987b). 
Populares (Conasupo) y la industria aceitera. La participación de estos actores estuvo definida por una política de fomento realizada esencialmente por el Gobierno a través de empresas públicas que proporcionaban créditos sin exigencia de garantías prendarias, seguro agrícola para producir, agroinsumos subsidiados y un canal gubernamental de comercialización basado en los precios de garantía.

\section{FIGURA 3}

Requerimientos de aceite de girasol en México

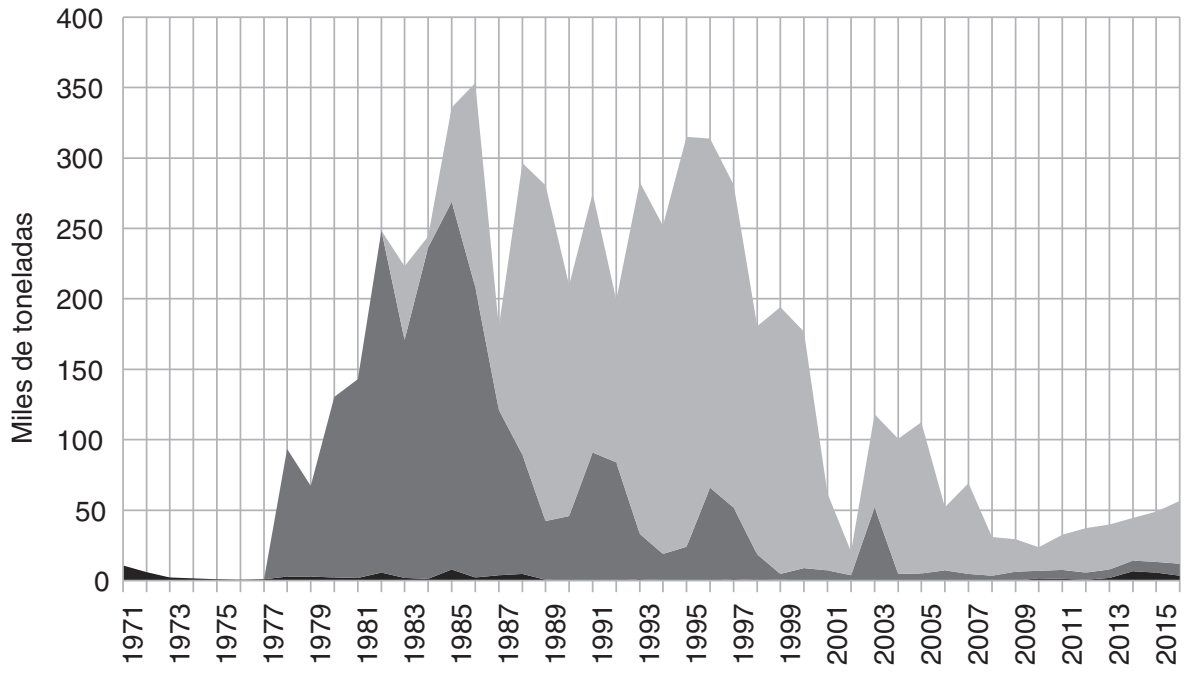

Importación de aceite

Importación de semilla (equivalente en aceite)

- Producción de semilla (equivalente en aceite)

Nota: se incluyen las importaciones de semilla y aceite, así como la producción nacional de semilla. Fuente: elaboración propia a partir de información de la FAO (2018).

Si bien con las acciones promovidas se logró establecer una extensa superficie con girasol, los resultados obtenidos fueron poco prometedores al obtenerse un rendimiento promedio de $528 \mathrm{~kg} / \mathrm{ha}$, por lo que gran parte de los agricultores dejaron de sembrar en los ciclos siguientes (Pascalis, 1980). Entre los factores que afectaron negativamente esta primera promoción de girasol se incluye: a) desconocimiento y baja disponibilidad de maquinaria para la siembra y cosecha; b) escasa experiencia en el manejo agronómico del cultivo; c) baja precipitación pluvial e irregular distribución; d) limitado manejo de plagas, particularmente de la palomilla de la cabeza (Homoeosoma electellum [Hulst]); e) establecimiento de siembras a destiempo; y f) insuficiente experimentación de las variedades sembradas (ASERCA, 1994; Ortegón, 1980; Robles, 1980). 
A pesar de las circunstancias señaladas en esta primera intervención, el Estado continuó promoviendo al cultivo de girasol entre los agricultores (Ortegón, 1980). Además, las instituciones de investigación públicas siguieron desarrollando conocimientos científicos y técnicos referentes al manejo del cultivo y a la obtención de materiales vegetales locales. De este modo, el girasol logró mantenerse activo por dos décadas (1971-1988). No obstante, la producción fue insuficiente para satisfacer la demanda de aceite de girasol de la industria y fue cubierta principalmente por las importaciones (Figura 3).

Si se consideran los tipos de eventos como indicadores de las funciones del SI (Cuadro 1), se puede resumir que el movimiento de fondo que generó un nicho de mercado para la producción de girasol y otras oleaginosas fue la transición de las grasas animales a las vegetales por razones de salud y la insuficiente oferta para responder a la demanda creciente de aceites vegetales [F5], donde el girasol se vislumbró como una alternativa por su alto contenido de aceite y su tolerancia a la sequía [F4]. Esta actividad productiva inició con el desarrollo de investigación [F2], cuyos resultados generaron expectativas del girasol como una opción para disminuir las importaciones de oleaginosas [F4]; posteriormente el Gobierno a través de varios actores movilizó recursos de distintos tipos para su producción en diferentes estados bajo un esquema de incentivos públicos [F6 y F3], aunado al interés que mostró la industria aceitera [F1].

\subsubsection{Declive y estancamiento del cultivo (1989-2007)}

Aunque la producción de girasol se sostuvo por varios años, hacia finales de la década de 1980 el declive del subsector figuró rápidamente cuando la superficie cultivada disminuyó abruptamente sin ningún crecimiento importante en los años posteriores. Esto a pesar de que la demanda de aceite y semilla de girasol para la industria continúo creciendo hasta mediados de 1990 (Figura 3).

Este estancamiento del cultivo se explica por un conjunto de factores, tales como: a) problemas técnicos en el cultivo; b) el arraigo de los productores a otros cultivos y el riesgo que supuso la inversión en un nuevo cultivo por el escaso conocimiento agronómico acumulado; c) el retraso tecnológico referente a la maquinaria agrícola para su siembra y cosecha; d) la dependencia de la institucionalidad gubernamental para producir y posteriormente vender la semilla; y e) la oportunidad de importar aceite o semilla de girasol. Por su impacto, se explican a mayor detalle los últimos dos factores.

A inicios de 1990 se implementaron varias reformas liberales, destacando: a) el inicio de reformas económicas (la entrada de México al Acuerdo General de Aranceles y Co- 
mercio y posteriormente la entrada en vigor del Tratado de Libre Comercio de América del Norte) con lo cual se liberó el comercio exterior de varios bienes agrícolas; y b) la intensificación de reformas estructurales agrícolas que incluyó la privatización o liquidación de empresas públicas de transformación y comercialización, y la eliminación de los subsidios a la producción [-F4 y -F5].

En este contexto, el girasol quedó en una posición competitiva frágil, pues implicó la desaparición del canal gubernamental de comercialización a través de Conasupo y la eliminación de subsidios a la producción. Además, la liberación del comercio interno posibilitó un fuerte flujo de importaciones de oleaginosas (aceite crudo y semillas) en condiciones más competitivas, esto a pesar de tener suficiente infraestructura tecnológica para el procesamiento de semillas.

Por otra parte, la industria aceitera en México se ha caracterizado por procesar diferentes semillas oleaginosas, pues los sistemas tecnológicos utilizados en la producción de aceite permiten el procesamiento de diferentes semillas en condiciones sustituibles (Arroyo, 1989). Además, los aceites pueden usarse alternativamente en aplicaciones similares. Esto origina la presencia de muchos sustitutos cercanos, elegibles de acuerdo con el precio, disponibilidad de suministros, funcionalidad y valor industrial [-F7].

A diferencia del girasol, la soya se posicionó en términos de superficie y demanda, explicado por la preferencia de esta oleaginosa en la industria aceitera, pues la pasta que se produce luego de la extracción del aceite es de gran valor en la elaboración de alimentos balanceados.

Todas las circunstancias señaladas finalmente provocaron que el cultivo de girasol no pudiera integrarse de manera sostenible a la cadena de valor de las oleaginosas. Su importancia como cultivo alternativo se desvaneció, lo cual también se manifestó en la pérdida de protagonismo de las instituciones de investigación en la generación y desarrollo de conocimiento [-F1 y -F2], pues los documentos de divulgación científicos-tecnológicos sobre el cultivo de girasol fueron disminuyendo paulatinamente (Figura 4).

Finalmente, a mediados de la década de 1990 los requerimientos nacionales de aceite y semilla de girasol, integrados principalmente por las importaciones y en menor medida por la producción nacional, empezaron a disminuir rápidamente, lo cual detuvo aún más el ya limitado crecimiento de la producción. En este panorama otra oleaginosa se incor- 
poró a la estructura de procesamiento de la industria aceitera, el aceite de canola ${ }^{5}$, el cual empezó a ganar participación en la producción de aceites vegetales. En 2007 este aceite alcanzó una participación del $43 \%$ en la producción nacional de aceites vegetales, seguido por la soya con $30 \%$ [-F5]. La preferencia de la canola al igual que la soya se relaciona con su valor industrial en la elaboración de alimentos balanceados.

\section{FIGURA 4}

Evolución de las publicaciones referentes a la investigación en el cultivo de girasol

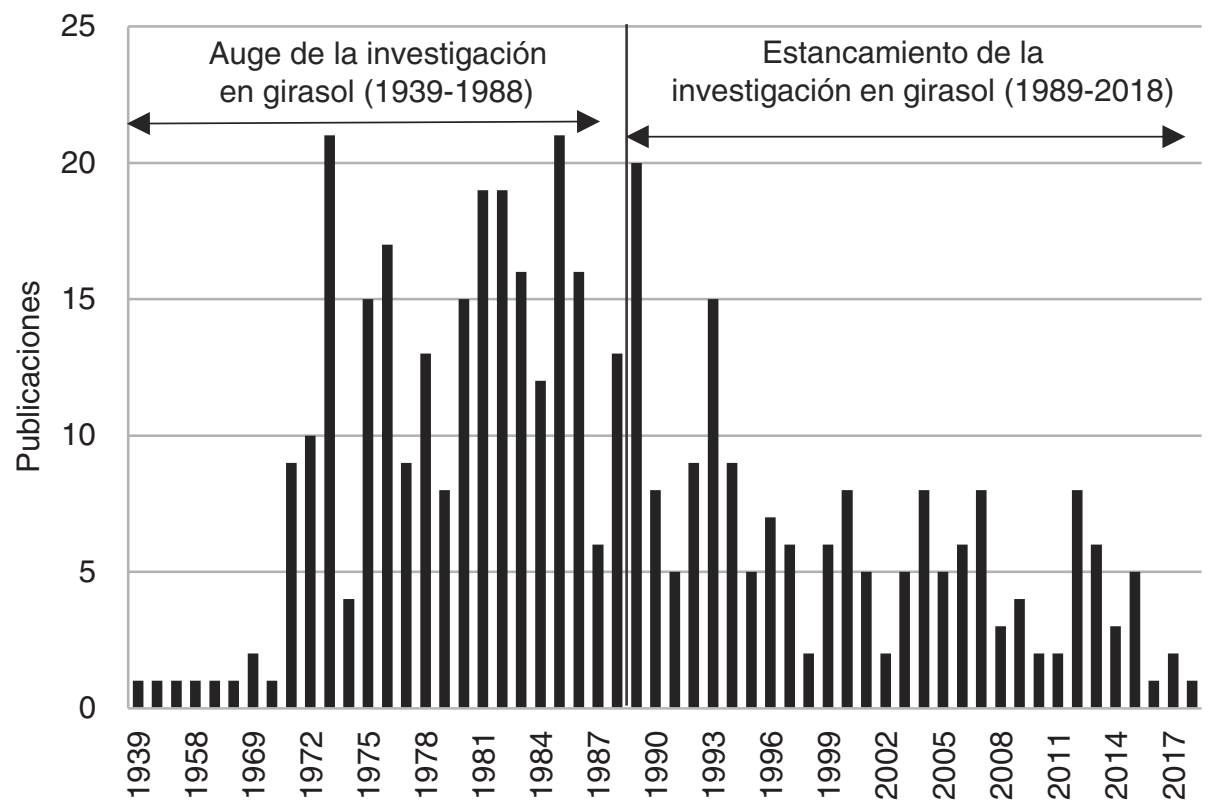

Fuente: elaboración propia a partir de información de repositorios digitales (ITSEM, UACh, UAAAN, UNAM, COLPOS 6 .

Dado que el girasol no se integró como un cultivo comercial, México ha sido tradicionalmente un importador neto de aceite y semilla de esta oleaginosa.

5. El cultivo de canola o colza (Brassica napus) también se ha tratado de incorporar al patrón de cultivos nacional con escasos resultados, por lo que la industria aceitera cubre sus necesidades principalmente con importaciones de semilla y aceite crudo.

6. ITSEM (Instituto Tecnológico y de Estudios Superiores de Monterrey); UACh (Universidad Autónoma Chapingo); UAAAN (Universidad Autónoma Agraria Antonio Narro); UNAM (Universidad Nacional Autónoma de México); COLPOS (Colegio de Postgraduados). 


\subsubsection{Reactivación (2008-actualidad)}

Después del estancamiento del girasol como cultivo comercial, en 2008 se recuperó el interés en su producción y se entró a una nueva etapa de intensificación. La demanda de los consumidores por productos más saludables, derivada del efecto negativo de las grasas saturadas y las grasas trans en la salud, las regulaciones que se han implementado con relación a su uso, así como los avances tecnológicos, han incentivado a la industria alimentaria mundial a la búsqueda de alternativas para la producción de alimentos libres de estas grasas.

Por ejemplo, en 2008 doce empresas transnacionales productoras de alimentos firmaron la iniciativa "Las Américas libres de grasas trans», con la finalidad de eliminar voluntariamente los ácidos grasos trans de los alimentos en 11 países de América Latina y el Caribe, incluido México.

En un contexto de análisis de salud pública, en el 2010 México ocupó el primer lugar a nivel mundial en obesidad y sobrepeso, lo cual se tradujo en la implementación de varios lineamientos de política relacionados con la distribución de alimentos y bebidas en las escuelas y a su etiquetado (Kaufer-Horwitz et al., 2018). Por tanto, las empresas productoras de alimentos se han visto obligadas a la búsqueda de opciones para distinguir a sus productos con el sello de saludables y amigables con el ambiente, y contribuir a disminuir la presencia de las enfermedades crónicas no transmisibles; tal es el caso de la industria de botanas.

La industria de botanas se interesó en el aceite de girasol alto oleico para utilizarlo en la elaboración de sus productos, como sustituto de la palmoleína (González Márquez et al., 2014; PepsiCo, 2010), con una demanda de aceite de al menos ciento veinte mil toneladas anuales (Molinos da Silva, 2010). Es de mencionarse que la palmoleína es un insumo importado con alto contenido de grasas saturadas y con una imagen negativa entre los consumidores por el impacto dañino que la palma de aceite causa al medio ambiente y por las malas condiciones de trabajo en las plantaciones (CBI, 2016).

Las características que hacen del aceite de girasol alto oleico una opción atractiva en la industria alimentaria son las siguientes. Este tipo de girasol se caracteriza por su alto contenido de ácidos grasos alto oleico cuya ventaja es su mayor estabilidad oxidativa frente a los genotipos con un alto contenido de ácidos grasos poliinsaturados. El alto contenido de ácidos grasos poliinsaturados es indeseable en elevados niveles, pues tienen una baja estabilidad termooxidativa (Garcés et al., 2009; Gupta, 2014). Para su uso a alta temperatura, este tipo de aceite debe ser parcialmente hidrogenado, lo cual proporciona ma- 
yor estabilidad, pero se generan ácidos grasos trans, considerados nutricionalmente indeseables por su relación con un mayor riesgo de presentar enfermedades cardiovasculares (Damude \& Kinney, 2008; Garcés et al., 2009; Gupta, 2014). Contrariamente, la composición del aceite de girasol alto oleico es deseable para propósitos de fritura, refinación y almacenamiento, pues no se requiere la hidrogenación y tiene mejores propiedades nutricionales comparado con los genotipos tradicionales y otros cultivos oleaginosos (Dimitrijevi et al., 2017; Kleingartner, 2015).

Además del interés por el girasol alto oleico para la producción de aceite, esta oleaginosa se ha valorado también como una opción en la rotación de cultivos para hacer frente a la problemática presentada en los monocultivos de frijol, sorgo, cebada, trigo y maíz, sistemas de producción cuyo uso continuo ha resultado en una menor productividad, problemas fitosanitarios, disminución de la rentabilidad y pérdida de biodiversidad en los paisajes agrícolas (FAO, 1995).

Ahora bien, el interés de la industria de botanas en el aceite de girasol alto oleico resultó en el despegue del cultivo. Su participación en la reactivación del girasol se resume en tres acciones: a) la solicitud y aprobación para que el girasol se incluyera dentro de las oleaginosas atendidas por el Comité Nacional Sistema-Producto Oleaginosas en el año 2008 (CONASIPRO, 2008); b) el establecimiento de cultivos demostrativos de girasol en diferentes estados en el año 2009, así como su producción comercial bajo el esquema de agricultura por contrato; y c) la generación de alianzas estratégicas con diferentes actores clave para promover el cultivo.

De este modo, el establecimiento de cultivos demostrativos en 2008 se dio en los estados de Baja California, Guanajuato, Sinaloa, Zacatecas, Durango y Jalisco. En los años posteriores, aquellas áreas donde el girasol alto oleico fue aceptado por los agricultores funcionó bajo un esquema de agricultura por contrato, con asesoría técnica y suministro de semilla mejorada (Molinos da Silva, 2010).

Para el 2011, el Banco Interamericano de Desarrollo (BID) y la industria de botanas pactaron el Proyecto de Agricultura Sustentable, el cual incluyó una inversión de cuarenta millones de dólares durante siete años para el desarrollo de proveedores en la siembra de hasta cincuenta mil hectáreas de girasol. No obstante, de acuerdo con las estadísticas de SIAP (2019) esta meta no se logró.

Aunado a la participación inicial de la industria de botanas, algunos mecanismos de política pública federal también aumentaron significativamente los incentivos para la pro- 
ducción de girasol, tal es el caso del proyecto Pro-Oleaginosas y el Subprograma de Apoyos Directos al Ingreso Objetivo, promovidos en 2009.

Los instrumentos de política estatal también han contribuido al despliegue de la producción de girasol, pues las equivalentes a las secretarías de agricultura en varios estados han integrado al girasol como una alternativa en el ordenamiento productivo, esto debido a que: a) es posible desarrollarlo bajo un esquema de agricultura por contrato; b) hay demanda de la semilla de girasol para la extracción de aceite; y c) por sus características agronómicas representa una opción en regiones donde los cultivos predominantes de temporal presentan problemas de productividad, fitosanitarios, de comercialización y de siniestralidad por factores climatológicos; por ejemplo, el frijol en Zacatecas y Durango, el sorgo en Morelos y Guanajuato, el trigo en Sonora, y el maíz y la cebada en el Estado de México, Hidalgo, Puebla y Tlaxcala.

No obstante, en el año 2014 la industria de botanas retiró el subsidio a la semilla y la asistencia técnica a los productores, por lo que su participación en la continuación del cultivo de girasol disminuyó, pero se contrarrestó con la colaboración de otros actores. Posterior a esto, ha destacado la colaboración entre la industria de botanas con una empresa transnacional proveedora de semillas, donde la función de esta última ha sido proveer de semilla de girasol alto oleico y de un paquete tecnológico a los agricultores, mientras que la industria de botanas compra la cosecha.

Los esfuerzos para la producción de girasol alto oleico han requerido de la intervención de varios tipos de actores, tales como instituciones de investigación (INIFAP, CIMMYT, universidades), instituciones de promoción y servicios de investigación no gubernamentales (Fundaciones Produce), actores gubernamentales de distintos ministerios relacionados con la difusión de apoyos (INAES, SAGARPA), proveedores de agroinsumos y otros. Algunas empresas productoras de aceite también han mostrado interés en este cultivo, tal es el caso de Aceites Especiales Tron Hermanos, Sesajal y AAK, quienes han empezado a comprar la producción generada en los estados.

\subsection{Funciones del sistema de innovación girasol alto oleico}

El interés de la industria de botanas por el aceite de girasol alto oleico y el impulso que el Gobierno federal y el de los estados ha mostrado al declararlo parte del reordenamiento productivo han hecho que el cultivo de girasol se desarrolle en diferentes partes del país en los últimos diez años. Sin embargo, la producción de 2009 a 2017 ha tenido altibajos y las regiones productoras aún no son consistentes; entre los años 2014 a 2017 se pasó 
de 15.624 a 7.216 hectáreas. Para entender estos resultados, el foco de análisis se puso en las funciones del SI, ya que dan una mayor claridad de lo que se ha estado haciendo, quiénes están involucrados y las oportunidades de mejora que se tienen. En la Figura 5 se resumen los eventos y funciones relacionados con la trayectoria que ha seguido el SI girasol alto oleico y que se detallan a continuación.

\section{FIGURA 5}

\section{Funciones del sistema de innovación girasol alto oleico}

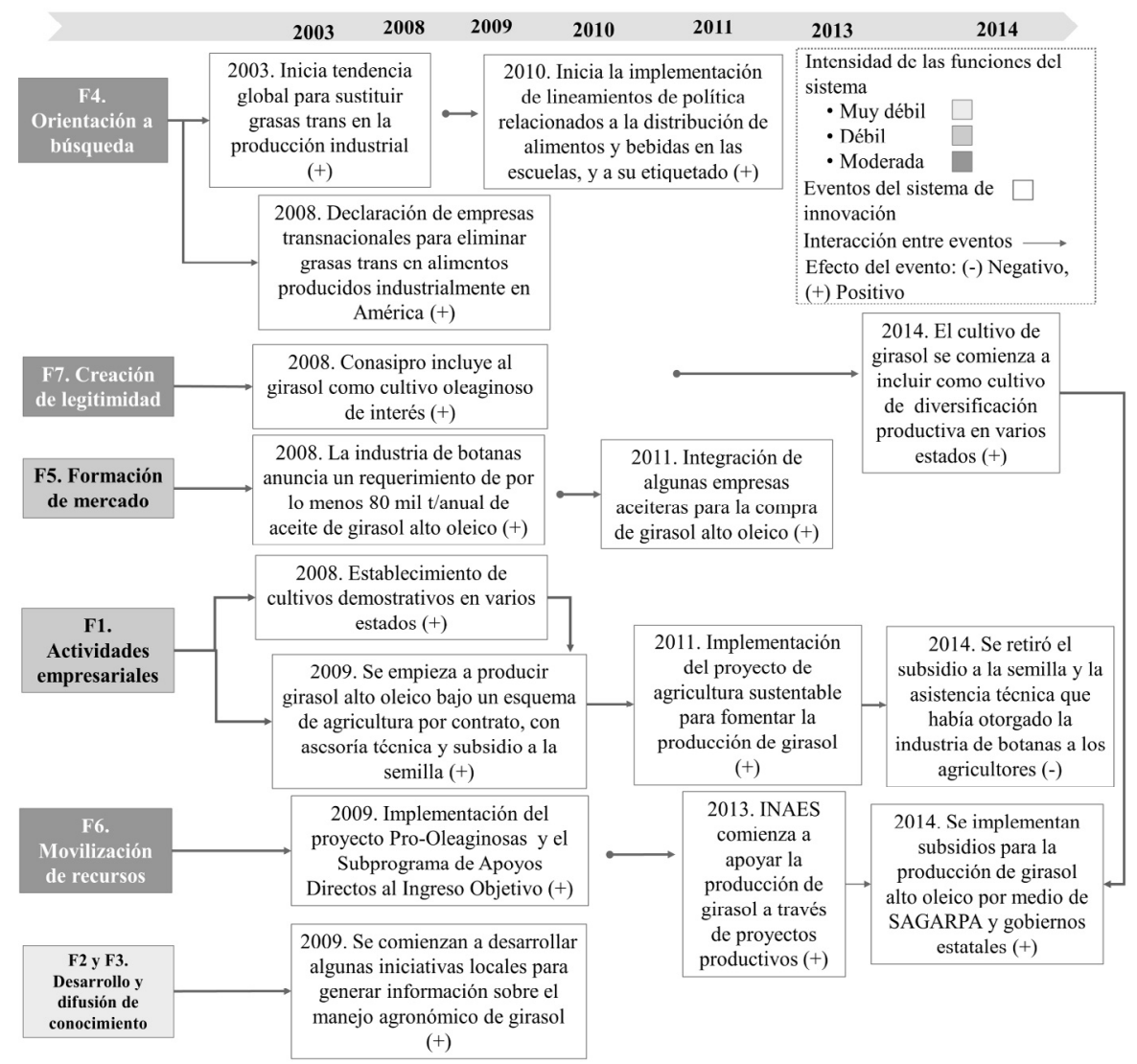

Fuente: elaboración propia a partir de información de campo y documental.

La búsqueda de alternativas para la producción de alimentos libres de grasas trans y saturadas en la industria alimentaria, incentivada por la implementación de algunas regulaciones para reducir las enfermedades crónicas no transmisibles [F4], ha generado un nicho de mercado para la producción de girasol alto oleico en México [F5] y el despliegue inicial de los actores que incipientemente configuran el SI. 
La integración de diferentes actores para impulsar el cultivo de girasol alto oleico ha sido similar en algunos rubros en todas las regiones, caracterizado por la intervención de la industria de botanas en colaboración con un proveedor de semillas [F1 y F6], apoyados por el Gobierno federal y estatal integrando al girasol como un cultivo de reconversión [F7] por lo cual ha sido objeto de diferentes tipos de apoyos y asesoría técnica [F6]. Además, en algunos estados ha sido importante la participación de las instituciones de investigación, universidades y otros actores para la validación y transferencia de tecnología relacionada con el cultivo [F2].

Así, todas las actividades del SI han estado presentes con diferente grado de intensidad. Los eventos más influyentes están relacionados con objetivos de política y apoyos vía subsidios u otros. No obstante, el avance en las funciones del SI hasta ahora solo ha permitido la reactivación del cultivo y cierta estabilidad, más no ha sido suficiente para asegurar su sostenibilidad.

Dado que las funciones de un SI son resultado de la interacción de los componentes estructurales, su desarrollo deficiente está relacionado con problemas con la presencia y calidad de estos componentes (Wieczorek \& Hekkert, 2012). En el Cuadro 2 se indican los principales bloqueos de las funciones del SI girasol y posteriormente se describen.

\section{CUADRO 2}

Principales bloqueos de las funciones más débiles o inconsistentes del SI girasol

Funciones del SI
F2 y F3. Desarrollo y difusión de conocimiento

F5. Formación de mercado

F1. Actividades empresariales

F6 y F7. Movilización de recursos y creación de legitimidad

\section{Bloqueos del SI}

- Limitada base de conocimientos y capital humano en el manejo agronómico y de cosecha y poscosecha.

- Mercado inmaduro e insuficiente diferenciación del aceite y de la pasta de girasol con respecto a otros aceites sustitutos.

- Competencia del cultivo de girasol con los cultivos tradicionales.

- Escasa participación de los actores relevantes (industria aceitera).

- Las acciones gubernamentales para promover el cultivo han sido intermitentes e inconsistentes.

- No existe una presión de la sociedad civil robusta para incentivar el uso de grasas sanas en la fabricación de alimentos procesados.

Fuente: elaboración propia a partir de información recabada en campo. 


\subsubsection{Funciones desarrollo y difusión de conocimiento (de intensidad muy débil, Figura 5)}

Existen una serie de restricciones en la producción primaria que deben ser solucionadas. La introducción de girasol alto oleico inició con un nulo conocimiento local en relación con el comportamiento de los híbridos importados y el manejo agronómico a seguir. La validación y la transferencia de la tecnología se han dado de manera parcial, solo en algunas regiones. La escasa validación de los híbridos apropiados a las regiones de producción y el insuficiente conocimiento sobre las prácticas adecuadas ha dado como resultado densidades y fechas de siembra inapropiadas, lo que resulta en pérdidas de productividad y aumento de costos unitarios de producción.

Adicionalmente, la baja disponibilidad y el uso inadecuado de la maquinaria para la siembra y cosecha de girasol han sido también limitantes en la producción del cultivo. La falta de equipo adecuado o bien calibrado para la cosecha ha ocasionado pérdidas de al menos el 30\% de la producción durante la trilla. Otro aspecto es el elevado costo de la semilla, insumo importado; por ejemplo, en la región productora del Estado de México e Hidalgo (información proporcionada por la SEDAGRO de ambos estados) se encontró que este insumo representa hasta el $20 \%$ de los costos totales.

\subsubsection{Funciones actividades empresariales y formación de mercado (de intensidad débil, Figura 5)}

En relación con la demanda de girasol alto oleico la participación de la industria de botanas se ha reducido. En el caso de la industria aceitera el involucramiento ha sido parcial, limitándose a la compra esporádica de la semilla; esto refleja que no hay un compromiso real con los agricultores. Esta situación se explica por la posibilidad que tiene la industria de satisfacer sus requerimientos de aceite de girasol a través del comercio exterior.

Otra limitante es la distancia de las zonas de producción respecto de la industria de extracción de aceite, pues su localización no siempre es cercana, lo cual aumenta los costos de movilización, sobre todo al considerar que el transporte por unidad de volumen se incrementa debido al bajo peso específico de la semilla. En el caso particular de la industria de botanas, la distancia adquiere particular relevancia, puesto que la extracción de aceite es una actividad realizada por un tercero y quizá esto explica su participación cada vez más deslindada. 
Por otro lado, la tendencia mundial en la regulación del contenido de grasas trans en los alimentos y la imagen negativa del aceite de palma eventualmente han incentivado el uso del aceite de girasol alto oleico en las empresas transnacionales de alimentos, lo cual ha derivado en la promoción del cultivo en México.

Del lado de la oferta un factor importante a considerar es que el girasol como cultivo alternativo compite por el uso del suelo con el patrón de producción tradicional. Por tanto, la producción de girasol debe ser más competitiva en términos de rentabilidad que el cultivo que sustituye; además debe ser compatible con las necesidades del agricultor. Por ejemplo, en la región productora del Estado de México algunos productores se han interesado en el cultivo de girasol como una opción para sustituir el cultivo de cebada, ya que durante los últimos años el acceso como proveedores de la industria maltera se ha dificultado.

\subsubsection{Funciones movilización de recursos y creación de legitimidad (de intensidad moderada pero inconsistente, Figura 5)}

Los apoyos de gobierno al impulso del cultivo de girasol han sido intermitentes y desordenados, lo cual se podría explicar, en parte, por el énfasis que los distintos funcionarios han puesto al promover este cultivo. Aunado a ello, en el país no existe una política relacionada con el contenido de grasas en los alimentos, únicamente existen medidas voluntarias por parte de las empresas con resultados limitados en comparación con otros países donde se han instaurado medidas obligatorias. Además, existe poco conocimiento o preocupación entre los consumidores acerca de las grasas trans (Pérez-Ferrer, Lock \& Rivera, 2010). Esta situación en el largo plazo limita el crecimiento potencial del aceite de girasol, pues su uso se justifica por el tema de salud.

En resumen, a pesar de los esfuerzos realizados por la industria de botanas para promover el cultivo de girasol, y la colaboración de otros actores, no se ha logrado estabilizar la producción de esta oleaginosa a nivel nacional. La formación y configuración del SI para apoyar el cultivo ha sido un proceso rezagado, caracterizado por una débil articulación entre el eslabón de los agricultores y el eslabón de la industria aceitera, así como la ausencia de actores orientados a la generación de aprendizajes colectivos en el manejo del cultivo y no solo focalizados al suministro de recursos materiales, lo cual ha dado como resultado un menor interés del cultivo entre los agricultores. Lo anterior se podría explicar como consecuencia de la ausencia de una política pública que impulse el cultivo de esta oleaginosa no solo por un asunto productivo, sino porque el uso de su aceite podría generar externalidades positivas en aspectos de salud pública. 


\subsection{Intermediarios de innovación en la sostenibilidad del girasol alto oleico}

A pesar de los limitados resultados del cultivo de girasol a nivel nacional, el estado de Zacatecas ha destacado por la sostenibilidad y crecimiento de esta oleaginosa, y ocupa el primer lugar con respecto a la superficie sembrada (30\%), seguido por Durango, Jalisco y San Luis Potosí.

En contraste con otros estados, la trayectoria que ha seguido el cultivo en Zacatecas se distingue por la integración de estructuras de apoyo con relaciones fuertes y la articulación de los agricultores con la agroindustria aceitera. Estos resultados se explican en buena parte por la presencia de un actor, el Grupo Agrocime (Figura 6).

\section{FIGURA 6}

\section{Configuración del sistema de innovación girasol, 2018}

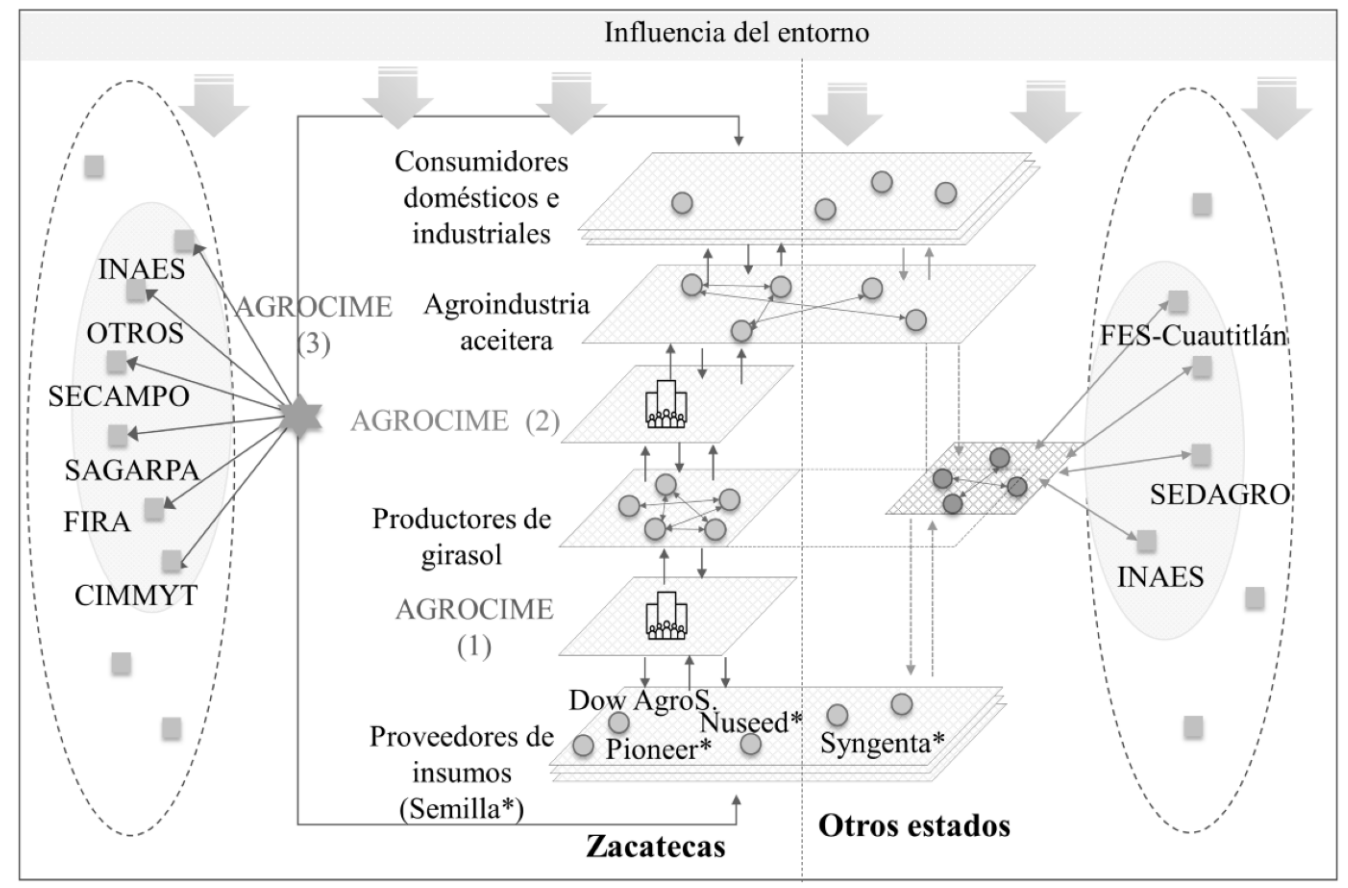

Fuente: elaboración propia a partir de información recabada en campo.

El Grupo Agrocime es una empresa de servicios especializados que surgió en el año 2004 y actualmente está integrado por cuatro unidades de negocio, que en su conjunto otorgan servicios de consultoría, asistencia técnica integral, transferencia de tecnología y comercialización de oleaginosas y granos básicos: a) Agrocime Consultans SC se dedica a 
la consultoría y asistencia técnica especializada; b) Consultores Especialistas Agomart, SC se enfoca a la generación de convenios de investigación con universidades y centros de investigación como Fundaciones Produce y Cimmyt; c) El Campo Agropecuaria SPR es una sociedad de producción rural que integra a productores de la región; y d) GA IrrigaciónIrrigación de Alta Tecnología se dedica a la instalación de sistemas de riego agrícola.

El Grupo Agrocime, como actor privado, con fines de lucro, de funcionamiento permanente y con amplias habilidades técnicas y de gestión ha contribuido a enfrentar las restricciones en la producción de girasol, comentadas anteriormente; su participación en este cultivo de girasol se resume en tres principales acciones.

1) Búsqueda y transferencia de conocimiento y tecnología a través de procesos participativos con los agricultores y otros actores.

La producción de girasol en Zacatecas se inició en el 2008 con el establecimiento de algunas hectáreas de girasol alto oleico. Sin embargo, los problemas en el manejo del cultivo y la falta de maquinaria para la siembra y la cosecha se hicieron presentes entre los agricultores. Como resultado, el Grupo Agrocime comenzó a involucrarse para apoyar a los agricultores, generando conocimiento técnico local para el manejo del cultivo.

Formalmente, la intervención de Agrocime en el cultivo de girasol se inició en 2009, cuando fue contratado por la industria de botanas por cinco años para dar seguimiento a este cultivo en Zacatecas y Durango. En este año la superficie sembrada en Zacatecas fue de 184 hectáreas, no obstante, para 2010 esta superficie pasó a tan sólo 18. Esta disminución en la superficie se debió a la presencia de problemas agronómicos en el cultivo que desincentivaron la producción de girasol entre los agricultores.

Dado que la información referente al manejo agronómico del girasol, particularmente para el tipo alto oleico, era reducida en el contexto de México, Agrocime promovió el desarrollo de investigación en colaboración con los agricultores. Esto culminó en un paquete tecnológico adecuado a las condiciones de la región de producción de Zacatecas. La investigación generada incluyó: a) la evaluación de híbridos de diferentes empresas productoras de semillas; b) evaluación de la densidad, profundidad y fechas de siembra; c) evaluación de métodos y productos para el control de plagas y enfermedades; d) evaluación de fuentes de fertilizantes, dosis y técnicas de aplicación; y f) adaptación a sembradoras y trilladoras.

El desarrollo de conocimiento local aplicado fue decisivo para reducir la incertidumbre entre los agricultores y en la generación de experiencia en el cultivo. Como resultado, 
en 2012 la superficie fue de 1.018 hectáreas, la cual continúo incrementándose para los siguientes años y se mantiene actualmente en 4.000 hectáreas (información proporcionada por Grupo Agrocime).

2) Articulación de la cadena de valor y acceso al mercado.

En 2013 el contrato entre Agrocime y la industria de botanas terminó, lo cual generó en Agrocime expectativas para ampliar la producción de girasol y buscar nuevos mercados. La continuidad de Agrocime permitió a los agricultores seguir cultivando girasol para un nuevo mercado, el de la industria aceitera.

El esquema de negocio de Agrocime para la producción de girasol es a través de agricultura por contrato, y opera de la siguiente manera: cada año Agrocime pacta las condiciones de compra-venta con las industrias aceiteras con respecto al volumen, calidad y precio de la semilla. Actualmente se tienen contratos con Aceites Especiales TH en Michoacán y Sesajal en Jalisco. Agrocime se encarga de abastecer de semilla a los agricultores. Al inicio del establecimiento del cultivo, un equipo de técnicos colabora con los agricultores para la calibración de las sembradoras y para iniciar con la implementación de un paquete tecnológico desarrollado por la empresa. Cuando es necesario, la empresa también proporciona financiamiento para la adquisición de insumos. Durante el ciclo productivo el equipo de técnicos da seguimiento al cultivo. Al momento de la cosecha se habilitan los centros de acopio (propiedad de los agricultores) para la recepción de la semilla, donde personal de Agrocime toma una muestra para realizar un análisis de calidad. Los parámetros que requiere la industria aceitera son, un máximo de $10 \%$ de humedad, un máximo de $2 \%$ de impurezas y un mínimo de $38 \%$ de aceite. De acuerdo con los parámetros obtenidos se fija un precio para el productor y Agrocime se encarga de la comercialización.

3) Creación de vínculos con diferentes actores, locales y externos, para integrar el cultivo de girasol al patrón de cultivos del agricultor.

La participación de Agrocime también ha incluido el despliegue de estructuras de apoyo que han dado legitimidad y consolidación al cultivo de girasol. En el año 2014 se logró que el girasol se integrara en el reordenamiento productivo del estado, como una alternativa diferente del cultivo de frijol, lo cual resultó en subsidios públicos a la semilla y otros mecanismos de financiamiento para la compra de sembradoras y cosechadoras. En este mismo año, Agrocime inició colaboraciones con MasAgro-CIMMYT para el desarrollo de girasol bajo agricultura de conservación. 
Por otro lado, a través de Agrocime se han gestionado otros apoyos relacionados con la adquisición de maquinaria y equipo y el desarrollo de infraestructura. Por ejemplo, se logró la construcción de tres centros de acopio de semilla con el apoyo del INAES (del Ministerio de Economía), con una capacidad conjunta de 4.000 toneladas. Asimismo, se consiguió la adquisición de varios equipos, tales como: bazucas, cribadoras móviles, sembradoras de precisión, trilladoras, entre otros. El apoyo de FIRA-Banco de México en colaboración con Agrocime también ha sido importante para disponer de líneas de crédito para capital de trabajo y de inversión fija para la producción, cosecha y acopio, así como el apoyo para el rembolso del pago de la asistencia técnica y capacitación.

Para facilitar la colaboración de los diferentes actores, Agrocime ha integrado a los agricultores en sociedades de producción rural, mediante las cuales también se hacen compras consolidadas de insumos.

En resumen, el esquema para la producción y comercialización de girasol que opera en Zacatecas a través del Grupo Agrocime es único en México. La intervención de Agrocime ha logrado compensar las debilidades existentes en la producción de girasol y dar viabilidad al cultivo frente a otras opciones productivas al integrar sus habilidades y recursos para generar investigación, validación y transferencia de tecnología, así como articular los vínculos entre los agricultores con actores de la cadena de valor y otros que la apoyan. Este entramado de relaciones que se han originado entre actores heterogéneos a partir de la intervención de Agrocime principian la configuración del SI girasol alto oleico.

\section{DISCUSIÓNY CONCLUSIONES}

En este trabajo se analizó la evolución del cultivo de girasol en México cuya introducción respondió a la demanda creciente de aceite y grasas vegetales como una alternativa viable en el sistema alimentario frente al remplazo de las grasas de origen animal por las de origen vegetal. Sus características agronómicas, particularmente las relacionadas a su amplia adaptabilidad a condiciones de baja precipitación, fueron clave para su elección.

De este modo, a partir de su introducción como cultivo comercial, en la década de 1970, el girasol ha transitado por tres etapas bien definidas, cada una con distinto desempeño. En el periodo inicial se dio la introducción y el auge del girasol con variedades importadas, cultivadas en varias regiones del país con apoyos gubernamentales y donde las instituciones de investigación ocuparon un papel dominante. 
No obstante, el cultivo entró en un segundo periodo que se caracterizó por la menor intervención del Estado en el sector agrícola y la entrada de reformas liberales, lo cual derivó en el cese paulatino de toda actividad relacionada con el cultivo y el abrupto descenso de la superficie sembrada. En este escenario la demanda de aceite de girasol por parte de la industria fue satisfecha por las importaciones. Esto pone en evidencia que la actividad productiva de girasol aún no generaba el abasto suficiente para la industria nacional al no ser sostenible, por lo cual la presencia del cultivo se explica primordialmente por la intervención del Estado, con un limitado interés de la industria de extracción de aceite en su promoción y continuidad. La participación limitada del girasol en la industria aceitera se explica por dos factores: a) su desarrollo ha estado subordinado a cultivos oleaginosos que primordialmente han sido promovidos por su valor para la obtención de otros productos; en un primer momento se promovió el algodón para obtener fibra y luego, a partir de 1960 se promovió la soya para generar pastas oleaginosas para la elaboración de alimentos balanceados y en forma complementaria producir aceite (Gómez Cruz, 1992; Sánchez Peña, 1992); b) en esta lógica de mercado, el girasol no pudo competir pues la pasta oleaginosa que se origina durante la extracción de su aceite es de menor valor.

En el tercer periodo se da la reactivación del cultivo a partir de la introducción de híbridos alto oleicos, promovidos por la iniciativa privada (industria de botanas) en respuesta a la demanda de aceites más saludables y funcionales. Esto en un contexto de salud pública debido al efecto negativo de las grasas trans por su relación con la presencia de enfermedades cardiovasculares. En esta etapa, que aún sigue desarrollándose, se tiene que las actividades realizadas permitieron la introducción del cultivo y cierta estabilidad. No obstante, las acciones públicas y privadas han sido insuficientes para desencadenar nuevas actividades e integrar nuevos actores con funciones distintas a la entrega de recursos de subsidios en activo que fomenten la generación y difusión de conocimiento y el desarrollo de un mercado más dinámico. Además, se destaca la relevancia de un intermediario de innovación en el funcionamiento adecuado del SI, esto al estimular la creación de vínculos entre actores heterogéneos y compensar la ausencia de actores públicos.

En este contexto, la producción de girasol tiene posibilidades de continuar, respaldada por tres factores. Primero, la demanda interna del aceite de girasol ha tenido un crecimiento positivo en los últimos años, por tanto, sigue habiendo un amplio margen para la producción de esta oleaginosa, donde la industria alimentaria hasta ahora depende primordialmente de las importaciones. Segundo, el reordenamiento productivo implementado en varios estados ha puesto al cultivo de girasol como una opción pertinente, ya sea como un cultivo de rotación o como opción de conversión. Tercero, en un tema de salud pública el uso de aceite de girasol tiene ventajas importantes sobre el de otras oleagino- 
sas. No obstante, para que estas perspectivas se cumplan es necesario desarrollar cuatro acciones:

En primer lugar, promover vínculos efectivos entre los diferentes actores de la cadena de valor para formular una visión conjunta y coordinar actividades de desarrollo. La integración más amplia de la industria aceitera puede contribuir a facilitar la operación de las cadenas de suministro con abasto más cercano a las industrias y con ello mejorar la competitividad del costo de girasol. Esta acción requiere de los incentivos adecuados de los gobiernos federal y estatal.

Segundo, promover y consolidar el desarrollo de conocimiento y de capacidades para el manejo del cultivo de girasol a nivel local. Es necesario considerar su origen como una tecnología exógena que necesita adecuarse a las condiciones de la región donde se introduce. Esto requiere propiciar vínculos entre diferentes actores con recursos y habilidades variados que permitan el desarrollo del SI. Hasta ahora, los actores que han participado en la integración del girasol se han focalizado principalmente en proporcionar subsidios de activos y, en menor medida, en la generación y difusión de conocimientos.

Tercero, para la introducción de girasol en una región determinada se debe evaluar el entorno en donde se quiere introducir el cultivo, considerando aspectos como el patrón de cultivos existente, el ciclo agrícola y la competitividad de estos.

Cuarto, a pesar de la demanda existente de aceite de girasol, el cultivo es vulnerable ante una mayor competitividad de otros aceites vegetales con menores precios y de mayor valor industrial, aunque de menor calidad y más nocivos a la salud. En este sentido, es necesario que se destaquen las cualidades funcionales y nutricionales del aceite de girasol alto oleico con respecto a otros aceites vegetales. En otros países el incentivo primordial para sustituir a los aceites hidrogenados y al aceite de palma en la industria alimentaria por el aceite de girasol alto oleico ha sido la formulación de políticas públicas donde se ha regulado el uso de grasas trans por temas de salud pública y legislado que el etiquetado de los productos incluya el nombre del aceite vegetal que contiene, en lugar de únicamente indicar que es elaborado a partir de aceite vegetal.

Finalmente, aunque el análisis presentado estuvo enfocado en el girasol para la producción de aceite, existen otros mercados potenciales que pueden ser explorados. Por ejemplo, la producción de girasol confitero, la producción de girasol para ensilaje utilizando las variedades nacionales o el girasol alto oleico orientado a otros mercados (por ejemplo, alimentos para aves). Asimismo, los hallazgos del presente estudio dan pautas a considerar al momento de impulsar cultivos de reconversión productiva. 


\section{AGRADECIMIENTOS}

Agradecemos a los dos revisores anónimos de la revista Historia Agraria y a los editores, por las valiosas recomendaciones durante el proceso de arbitraje. Este trabajo se concretó gracias al financiamiento de la Dirección General de Investigación y Posgrado, de la Universidad Autónoma Chapingo con el proyecto 20003-DTT-61 administrado por el CIESTAAM.

\section{REFERENCIAS}

Amador, V. (1969). Estudio agro-industrial del cultivo de girasol en México. Tesis. Chapingo: Escuela Nacional de Agricultura.

Anandajayasekeram, P. \& Gebremedhin, B. (2009). Integrating Innovation Systems Perspective andValue Chain Analysis in Agricultural Research for Development: Implications and Challenges. Addis Ababa: International Livestock Research Institute. (International Livestock Research Institute: Improving Productivity and Market Success of Ethiopian Farmers Project, 16).

Arocena, R. \& Sutz, J. (2003). Subdesarrollo e innovación: Navegando contra el viento. Madrid: Cambridge University Press.

Arroyo, G. (1989). La pérdida de la autosuficiencia alimentaria y el auge de la ganadería en México. México, DF: Plaza y Valdés.

ASERCA (1994). Girasol y Algodón. Claridades Agropecuarias, (15).

BANCo Mundial (2008). Incentivar la innovación agrícola: Cómo ir más allá del fortalecimiento de los sistemas de investigación. Bogotá: Mayol.

Bancomext (1955). Manteca de cerdo. Mercados y Productos, 198-201.

Bergek, A., Jacobsson, S., Carlsson, B., Lindmark, S. \& Rickne, A. (2008). Analyzing the Functional Dynamics of Technological Innovation Systems: A Scheme of Analysis. Research Policy, 37 (3), 407-429.

Carlsson, B., Jacobsson, S., Holmén, M. \& Rickne, A. (2002). Innovation Systems: Analytical and Methodological Issues. Research Policy, 31 (2), 233-245.

CBI (2016). Sunflower Oil in Europe, 1-13. https://www.cbi.eu/market-information/ vegetable-oils/sunflower-oil/

Clark, N., Hall, A., Sulaiman, R. \& Naik, G. (2003). Research as Capacity Building: The Case of an NGO Facilitated Post-Harvest Innovation System for the Himalayan Hills. World Development, 31 (11), 1845-1863.

CONASIPRO (2008). Celebración de la 13a sesión del Comité Nacional. Oleaginosas en Cadena, 7-8. 
Damude, H. G. \& Kinney, A. J. (2008). Enhancing Plant Seed Oils for Human Nutrition. Plant Physiology, 147 (3), 962-968.

Dimitrijevi , A., Imerovski, I., Miladinovi , D., Cvej , S., Joci, S., Zeremski, T. \& SaKa, Z. (2017). Oleic Acid Variation and Marker-Assisted detection of Pervenets Mutation in High- and Low-Oleic Sunflower Cross. Crop Breeding and Applied Biotechnology, 17 (3), 235-241.

Downs, S. M., Thow, A. M. \& LeEder, S. R. (2013). The Effectiveness of Policies for Reducing dietary Trans Fat: A Systematic Review of the Evidence. Bulletin of the World Health Organization, 91 (4), 262-269.

Food AND Agricultural Organization (FAO) (1995). Balance de la Revolución Verde: Nuevas necesidades, nuevas estrategias. Ceres, (154). http://www.fao.org/3/ v6640s/v6640s00.htm

Food and Agricultural Organization (FAO) (2018). FAOSTAT. Food and Agriculture Organization of the United Nations. http://faostat.fao.org/

Flores, J. J., SÁnChez PeÑa, V. \& SANToyo,V. H. (1986). La integración agricultura-industria en la producción de oleaginosas y aceites en el sur de Sonora. Revista de Geografía Agrícola, 113-142.

FREEMAN, C. (2004). Technological Infraestructure and International Competitiveness. Industrial and Corporate Change, 13 (3), 541-569.

Fucickovsky, L. (1976). Enfermedades y plagas de girasol en México. Chapingo: Escuela Nacional de Agricultura.

Gallegos, C. C. (1970). Latest Developments and Trends in Sunflower Production in Mexico. $4^{\text {th }}$ International Sunflower Conference. Memphis, 23-25 de junio.

Gallegos, C. C. \& Elizondo, H. M. DE (1972). El cultivo de girasol. México, DF: Instituto Nacional de Investigaciones Científicas.

Garcés, R., Martínez-Force, E., SAlas, J. J. \&Venegas-Calerón, M. (2009). Current Advances in Sunflower Oil and its Applications. Lipid Technology, 21 (4), 79-82.

Gómez Cruz, M. A. (1992). Agroindustria, Estado y progreso científico-técnico en la agricultura mexicana. En R. Schwentesius Rindermann \& M. A. Gómez CruZ (Eds.), Implicaciones del progreso tecnológico en la agricultura de países en desarrollo (pp. 162-178). Texcoco: Humboldt Universitat zu Berlin/Universidad Autonoma Chapingo.

González Márquez, J. C., Hernández Castañeda, U., Orozco, R. \& Sánchez ValDEZ, J. (2014). El resurgimiento de la producción de girasol en Zacatecas. El Campirano, (99), 10-11. https://issuu.com/grupoinformador/docs/marzo_2014

GuPTA, M. K. (2014). Sunflower Oil: History, Applications and Trends. Lipid Technology, 26 (11-12), 260-263.

Hall, A., Bockett, G., Taylor, S., Sivamohan, M.V. K. \& Clark, N. (2001). Why Research Partnership Really Matter: Innovation Theory, Institutional Arrangements 
and Implications for Developing New Technology for the Poor. World Development, 29 (5), 783-797.

Hall, A., Mytelka, L. \& Oyeyinka, B. (2005). Innovation Systems: Implications for Agricultural Policy and Practice. ILAC Brief, (2), 1-4.

Hekkert, M. P., Negro, S. O., Heimeriks, G. \& Harmsen, R. (2011). Technological Innovation System Analysis: A Manual for Analysts. Utrecht University, Report for Joint Research Center, Energy Institute.

Hekkert, M. P., Suurs, R. A. A., Negro, S. O., Kuhlmann, S. \& Smits, R. E. H. M. (2007). Functions of Innovation Systems: A New Approach for Analysing Technological Change. Technological Forecasting and Social Change, 74 (4), 413-432.

Hekkert, M. P. \& Negro, S. O. (2009). Functions of Innovation Systems as a Framework to Understand Sustainable Technological Change: Empirical Evidence for Earlier Claims. Technological Forecasting and Social Change, 76 (4), 584-594.

INEGI, SECOFI \& SISVAN (1988). Abasto y comercialización de productos básicos: Oleaginosas.

INIFAP (2004). Guía para la producción de girasol en el Norte de Tamaulipas.

KaUfer-Horwitz, M., Tolentino-Mayo, L., JÁuregui, A. et al. (2018). Sistema de etiquetado frontal de alimentos y bebidas para México: Una estrategia para la toma de decisiones saludables. Salud Pública de México, 60 (4), 479-486.

Kleingartner, L. (2015). U.S. and Canada Perspectives on Sunflower Production and Processing. En E. Martínez-Force, N. Turgut \& J. J. SAlas (Eds.), Sunflower: Chemistry, Production, Processing, and Utilization (pp. 491-516). Urbana: AOCS Press. KieINGARTNER, L. W. (2002). NuSUn SUNFlower Oil: REDIRECTION OF AN INDUSTRY. EN J. JANick \& A. Whipkey (Eds.), Trends in New Crops and New Uses (pp. 135-138). Alexandria: American Society for Horticultural Science Press.

Klerkx, L., Mierlo, B. van \& LeEuwis, C. (2012). Evolution of Systems Approaches to Agricultural Innovation: Concepts, Analysis and Interventions. En I. DARNHOFER, D. P. GibBon \& B. Dedieu (Eds.), Farming Systems Research into the 21st Century: The New Dynamic (pp. 431-455). Dordrecht: Springer.

Lamprinopoulou, C., Renwick, A., Klerkx, L., Hermans, F. \& Roep, D. (2014). Application of an Integrated Systemic Framework for Analysing Agricultural Innovation Systems and Informing Innovation Policies: Comparing the Dutch and Scottish Agrifood Sectors. Agricultural Systems, (129), 40-54.

Lundvall, B. (2015). The Origins of the National Innovation System Concept and its Usefulness in the Era of the Globalizing Economy. $13^{\text {th }}$ Globelics Conference. La Habana, 23-26 de septiembre.

Matsaert, H., Ahmed, Z., Islam, N. \& Hussain, F. (2005). Using Actor-Oriented Tools to Analyse Innovation Systems in Bangladesh. Participatory Learning and Action, (51), 100-110. 
Molinos Da Silva, C. (2010). Oportunidad de negocio con el cultivo de girasol ( $\mathrm{He}-$ lianthus annus L.) alto oleico para PepsiCo-Sabritas. En J. J. MARTínez Ríos, M.VÁzQUEZ NaVARro, R. SANTANA \& A. MARTínez Ríos (Eds.), Memoria de la XXII semana internacional de Agronomía FAZ-UfED (pp. 1-5). Durango: Universidad Juárez del Estado de Durango.

Monge-Rojas, R., Colón-Ramos, U., Jacoby, E. \& Mozaffarian, D. (2011).Voluntary Reduction of Trans-Fatty Acids in Latin America and the Caribbean: Current Situation. Rev Panam Salud Publica, 29 (2), 126-129.

Ortegón, A. S. (1980). Situación del cultivo de girasol en México. En Instituto NACIONAL DE INVESTIGACIONES AGRARIAS (Ed.), IX Conferencia Internacional del Girasol (pp. 45-49). Madrid: Servicio de Publicaciones Agrarias.

ORTEGón, A. S. (1982). Logros y aportaciones de la investigación agrícola en ajonjolí, cacahuate y girasol. México, DF: Instituto Nacional de Investigaciones Agrícolas.

Ortegón, A. S. \& Escobedo, A. (1987a). Programa de girasol: Proyecto I: Formación de híbridos y variedades de girasol (mejoramiento genético): Resultados y avances (19781985). Río Bravo: Secretaría de Agricultura y Recursos Hidráulicos/Instituto Nacional de Investigaciones Forestales, Agrícolas y Pecuarias/Centro de Investigaciones Agrícolas del Golfo Norte.

Ortegón, A. S. \& Escobedo, A. (1987b). Programa de girasol: Proyecto II: Desarrollo de tecnología para el cultivo de girasol: Resultados y avances (1978-1985). Río Bravo: Secretaría de Agricultura y Recursos Hidráulicos/Instituto Nacional de Investigaciones Forestales, Agrícolas y Pecuarias/Centro de Investigaciones Agrícolas del Golfo Norte.

Ortiz, O., Orrego, R., Pradel, W., Gildemacher, P., Castillo, R., Otiniano, R., GaBriel, J., Vallejo, J., Torres, O., Woldegiorgis, G., Damene, B., Kakuhenzire, R., KASAHIJA, I. \& KaHIU, I. (2013). Insights into Potato Innovation Systems in Bolivia, Ethiopia, Peru and Uganda. Agricultural Systems, (114), 73-83.

Pascalis, M. G. (1980). Ensayo de rendimientos entre 37 variedades e hibridos de girasol (Helianthus annus L.) de Rumanía y Yugoslavia bajo las condiciones ecológicas en Apodaca, N. L., verano de 1979. Monterrey: Instituto Tecnológico y de Estudios Superiores de Monterrey.

PepsiCo (2010). Desempeño con sentido: Reporte de sustentabilidad PepsiCo México 2009-2010. México, DF: PepsiCo.

Pérez-Ferrer, C., Lock, K. \& Rivera, J. A. (2010). Learning from International Policies on Trans Fatty Acids to Reduce Cardiovascular Disease in Low- and Middle-Income Countries, using Mexico as a Case Study. Health Policy and Planning, 25 (1), 39-49.

ReIG, N. (1985). Las tendencias alimentarias a largo plazo en México: 1950-1984: Problemas del desarrollo. Revista Latinoamericana de Economía, 16 (61), 9-64.

Robles, R. (1980). Producción de oleaginosas y textiles. México, DF: Limusa. 
SÁnCHez Herrera, S. \& Gómez CruZ, M. A. (1992). Sistema agroindustrial producción intensiva de carne y huevo: Situación, problemática y alternativas. En R. SCHWENTESIUS \& M. A. Gómez CRUZ (Eds.), Implicaciones del progreso tecnológico en la agricultura de paises en desarrollo (pp. 195-202). Texcoco: Humboldt Universität zu Berlin/Universidad Autónoma Chapingo.

SÁNCHEZ PEÑA, V. (1992). Desarrollo agroindustrial e integración de los productores en la agroindustria aceitera en México. En R. Schwentesius \& M. A. Gómez CruZ (Eds.), Implicaciones del progreso tecnológico en la agricultura de países en desarrollo (pp. 578-589). Texcoco: Humboldt Universität zu Berlin/Universidad Autónoma Chapingo. SÁNCHeZ PeÑA, V. (1993). El sistema agroindustrial oleaginosas-aceites en México. En J. De la Fuente, R. Ortega \& M. Samano (Eds.), Agricultura y agronomía en México: 500 años (pp. 361-374). Texcoco: Universidad Autónoma Chapingo.

SECRETARía DE ECONOMía (2018). Sistema de Información Arancelaría Vía Internet (SIAVI). http://www.economia-snci.gob.mx/

SHIELDS, D. S. (2010). Prospecting for Oil. Gastronomica, 10 (4), 25-34.

SERVICIO DE INFORMACIÓN Agroalimentaria y PESQuera (SIAP) (2019). Sistema de Información Agroalimentaria de Consulta (SIACON). https://www.gob.mx/siap/prensa/ sistema-de-informacion-agroalimentaria-de-consulta-siacon?idiom=es

Spielman, D. J., Ekboir, J. \& Davis, K. (2009). The Art and Science of Innovation Systems Inquiry: Applications to Sub-Saharan African Agriculture. Technology in Society, 31 (4), 399-405.

TORRE, J. DE LA (1980). Análisis y perspectivas del cultivo de girasol (Helianthus annus) en México. Tesis. Guadalajara: Universidad de Guadalajara.

VeIT, H. Z. (2019). Eating Cotton: Cottonseed, Crisco, and Consumer Ignorance. The Fournal of the Gilded Age and Progressive Era, 18 (4), 397-421.

WieczoreK, A. J. \& HeKkeRT, M. P. (2012). Systemic Instruments for Systemic Innovation Problems: A Framework for Policy Makers and Innovation Scholars. Science and Public Policy, 39 (1), 74-87.

World Health Organization (2018). Replace Trans Fat: An Action Package to eliminate Industrially-Produced Trans-Fatty Acids. https://www.who.int/docs/defaultsource/documents/replace-transfats/replace-action-package.pdf 